\title{
Effect of glucocorticoids on indomethacin-induced gastric ulcer in the adult male albino rat - histological, morphometric and electron microscopy study
}

Sherif Mohamed Zaki, Enas Ahmed Mohamed

Department of Anatomy, Faculty of Medicine, Cairo University, Egypt

Submitted: 23 May 2011

Accepted: 21 March 2012

Arch Med Sci 2014; 10, 2: 381-388

DOI: 10.5114/aoms.2012.28807

Copyright $\odot 2014$ Termedia \& Banach

\section{Abstract}

Introduction: Indomethacin is a non steroidal anti-inflammatory drug (NSAID) which is capable of producing injury to gastric mucosa. To prevent of NSAID-induced gastropathy, it is important to evaluate the risk factors. One of them is steroid. The aim is to study time dependent effects of glucocorticoids (GC) on indomethacin induced gastric ulcer.

Material and methods: Forty-nine albino rats were used. They were divided into control and experimental groups. The experimental group was subgroup I (rats were given indomethacin and were sacrificed 1 day after drug intake), subgroup II (rats were given indomethacin + dexamethasone and were sacrificed 1 day after drug intake), subgroup III (rats were given indomethacin + dexamethasone and were sacrificed 3 days after drug intake) and subgroup IV (rats were given indomethacin + dexamethasone and were sacrificed 7 days day after drug intake). Histological, scanning electron microscopy and morphometric studies were used.

Results: Indomethacin induced gastric ulceration with shredding of the superficial epithelial cells. The fundic glands were dilated in the subgroups II, III, IV. The surface epithelial cells were shredded and the ulcer sizes were big in subgroup IV. All subgroups exhibited abnormal surface epithelial cells within the gastric ulcer area.

Conclusions: Indomethacin is capable of producing injury to gastrointestinal mucosa. With prolonged use of GC the surface epithelial cells became more affected and the ulcer sizes became bigger. Concomitant use of both medications will delay the healing of the indomethacin induced gastric ulcer and induce more gastric complication.

Key words: indomethacin, glucocorticoids, gastric ulcer.

\section{Introduction}

Indomethacin is a non-steroidal anti-inflammatory drug (NSAID), which is capable of producing injury to gastrointestinal mucosa in experimental animals and humans, and its use is associated with a significant risk of haemorrhage, erosions, and perforation of both gastric and intestinal ulcers [1].

To make a strategy for the prevention of NSAID-induced gastropathy, it is important to evaluate the risk factors of each patient. Multiple factors have been identified that increase risk for NSAID-related upper gastrointestinal complications. One important risk factor is steroids [2].

Glucocorticoids (GC) are a class of steroid hormones that bind to the GC receptor, which is present in almost every vertebrate animal cell [3].

\author{
Corresponding author: \\ Sherif Mohamed Zaki MD \\ Anatomy Department \\ Faculty of Medicine \\ Cairo University \\ El-Kasr Al Aini Street \\ Cairo, Egypt \\ Phone: +20226706317, \\ $+201227457431$ \\ E-mail: zaky.sherif@yahoo.com
}


The GC preparations form one of the cornerstones of the modern medical pharmacopeia. Oral GC are prescribed to over $7 \%$ of hospitalized patients. Of this group, some $17 \%$ may experience adverse effects [4].

Administration of GC to experimental animals can result in formation of acute gastric erosion [5]. In some cases, their administration to experimental animals can attenuate gastric erosion formation [6]. The GC may have dual action on the stomach: gastroprotective and ulcerogenic. In physiological conditions GC have an adaptive effect on the stomach and, therefore, are gastroprotective, while in some situations (probably in pathological conditions) their action on the gastric mucosa may become pro-ulcerogenic [7].

The aim of the present work was to study the time-dependent effects of GC on indomethacin-induced gastric ulcer in the adult male albino rat. This was done through histological and scanning electron microscopic studies (SEM). Morphometric study was also done using the image analyser.

\section{Material and methods}

Forty-nine adult male Sprague Dawley rats (animal house, Faculty of Medicine, Cairo University), weighing 250-300 g, were used. Five animals were housed per cage, and the animals were acclimatized to standard laboratory conditions (12:12-h light-dark cycle, temperature $20^{\circ} \mathrm{C}$, fed ad libitum and allowed free water supply). The animals were deprived of food but allowed free access to tap water for $24 \mathrm{~h}$ before the experiment. Only male rats were used in this study to exclude possible sex differences. The experiment was performed according to the Helsinki agreement on the guiding principles for research involving animals and human beings. The current study was reviewed by the ethical committee on experiments on animals of the Faculty of Medicine, Cairo University. The committees have the responsibility to weigh the suffering of laboratory animals against the benefits of research. They approved the current work.

The animals were divided into control and experimental groups as follows: the control group consisted of 9 rats. They received the vehicle at the corresponding time as the experimental group. Three rats were sacrificed after 1, 3, 7 days with the experimental subgroups. The experimental group consisted of 40 rats. This group was subdivided into 4 subgroups each of which consisted of 10 rats: subgroup I: the rats were given indomethacin and were sacrificed one day after drug intake; subgroup II: the rats were given indomethacin + dexamethasone and were sacrificed one day after drug intake; subgroup III: The rats were given indomethacin + dexamethasone and were sacrificed 3 days after drug intake; subgroup IV - the rats were given indomethacin + dexamethasone and were sacrificed 7 days after drug intake.

Indomethacin was given as a single dose (48 mg/ $\mathrm{kg}$ ) dissolved in normal saline to induce a maximum level of acute gastric ulcer $[8,9]$. Dexamethasone $(1 \mathrm{mg} / \mathrm{kg}$ ) was dissolved in 1,2-propylene glycol and injected once intraperitoneally [7].

The animals were sacrificed by a high dose of ether. The fundic and body regions of the stomach were specifically selected since it is the most frequent site of indomethacin-induced lesions [10]. These regions were excised in toto using a pair of scissors between oesophageal and pyloric ends of the body. The mucosal surface of the stomach was exposed by making a cut along the greater curvature.

\section{Light microscopic study}

Part of the obtained specimen was fixed in buffered formol saline, processed for paraffin sections of $5 \mu \mathrm{m}$ thickness and sections were stained with haematoxylin and eosin $(\mathrm{H}+\mathrm{E})$ and periodic acidSchiff (PAS) stains for histological study [11].

The $\mathrm{H}+\mathrm{E}$ and PAS sections were all examined and photographed using a Canon digital camera, attached to an IBM computer system.

\section{Ultrastructural study}

The other parts of obtained specimens were prepared for SEM [12]. Examination and photography of specimens were carried out using a Jeom-1400 transmission electron microscope. The examination was done in the electron microscopy department, Faculty of Agriculture, Cairo University.

\section{Image analyser study}

The sections were examined using Leica Qwin 500 image analysis software on an IBM operated computer system.

Four gastric preparations with PAS reaction from each rat (with a total of 40 gastric preparations in each experimental subgroup) were subjected to quantitative studies. The optical density of PAS reaction was measured in the cytoplasm of surface columnar and mucous neck cells using the grey measure menu in 10 measuring frames in each specimen using an objective lens of magnification 20 , i.e. at a total magnification of 200 after grey calibration. The optical density of PAS reaction was done by transforming the image into a grey image and then masking the positive areas by a blue binary colour (Figure 1). The parameters chosen were the number of pixels, sum of grey and mean grey. The optical density was expressed in the form of mean grey that was obtained by the following equation: 


$$
\text { Mean grey }=\frac{\text { No. of pixels }}{\text { Sum of grey }} \text {. }
$$

The data were collected and studied using analysis of variance (two-tailed ANOVA) to compare between the different groups using SPSS 17 statistical program. Values of $p<0.05$ were regarded as significant.

\section{Results}

\section{Results of $\mathrm{H}+\mathrm{E}$ stained sections}

Histological examination of the stomach of the control rats exhibited the normal architecture of the fundic mucosa. The fundic glands were lined with mucous neck cells, oxyntic cells and peptic cells and they opened to the surface in gastric pits. The mucous neck cells were simple columnar epithelium with pale staining. The oxyntic cells were large and rounded with extensive acidophilic cytoplasm and centre rounded nuclei. The peptic cells had basophilic cytoplasm; their nuclei were basal and rounded. The surface mucosal cells appeared pale with basal oval nuclei (Figure $2 \mathrm{~A}$ ).

Ulceration and cellular infiltrations were characteristic findings in the experimental subgroups. Examination of the stomach of the experimental rat subgroup I showed the presence of ulceration, and deep erosions with shedding of the superficial epithelial cells (Figure 2 B). Cellular infiltration was observed in the connective tissue corium of the basal part of the fundic mucosa (Figure $2 \mathrm{C}$ ).
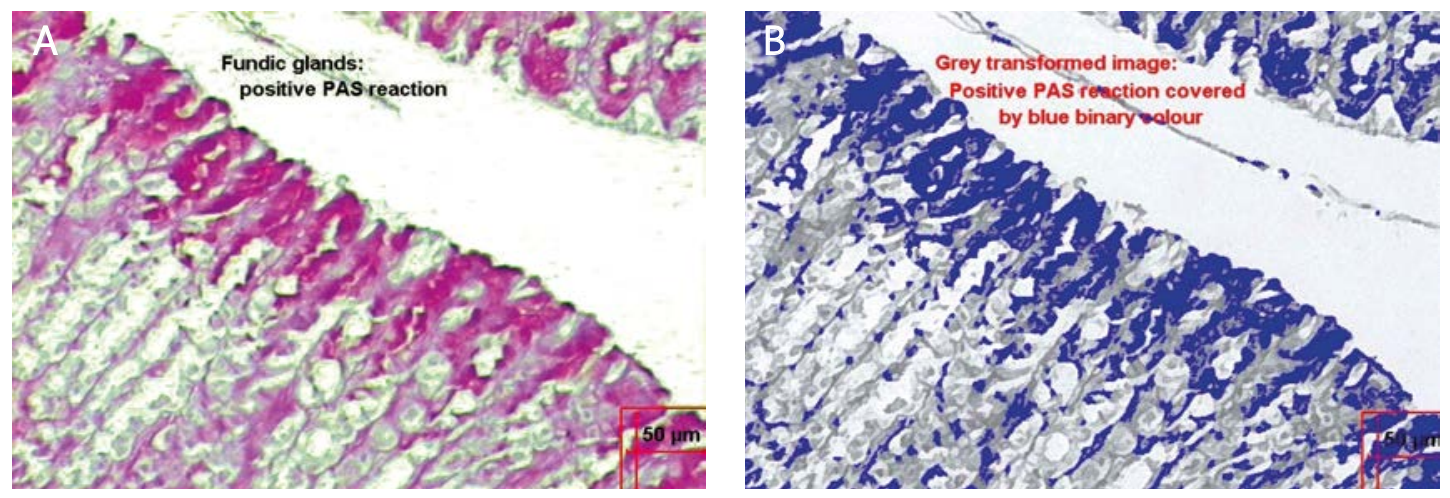

Figure 1. A - PAS reaction in the fundic glands of the stomach (PAS, 400x). B - The positive PAS reaction areas were masked by a blue binary colour (PAS, 400x)
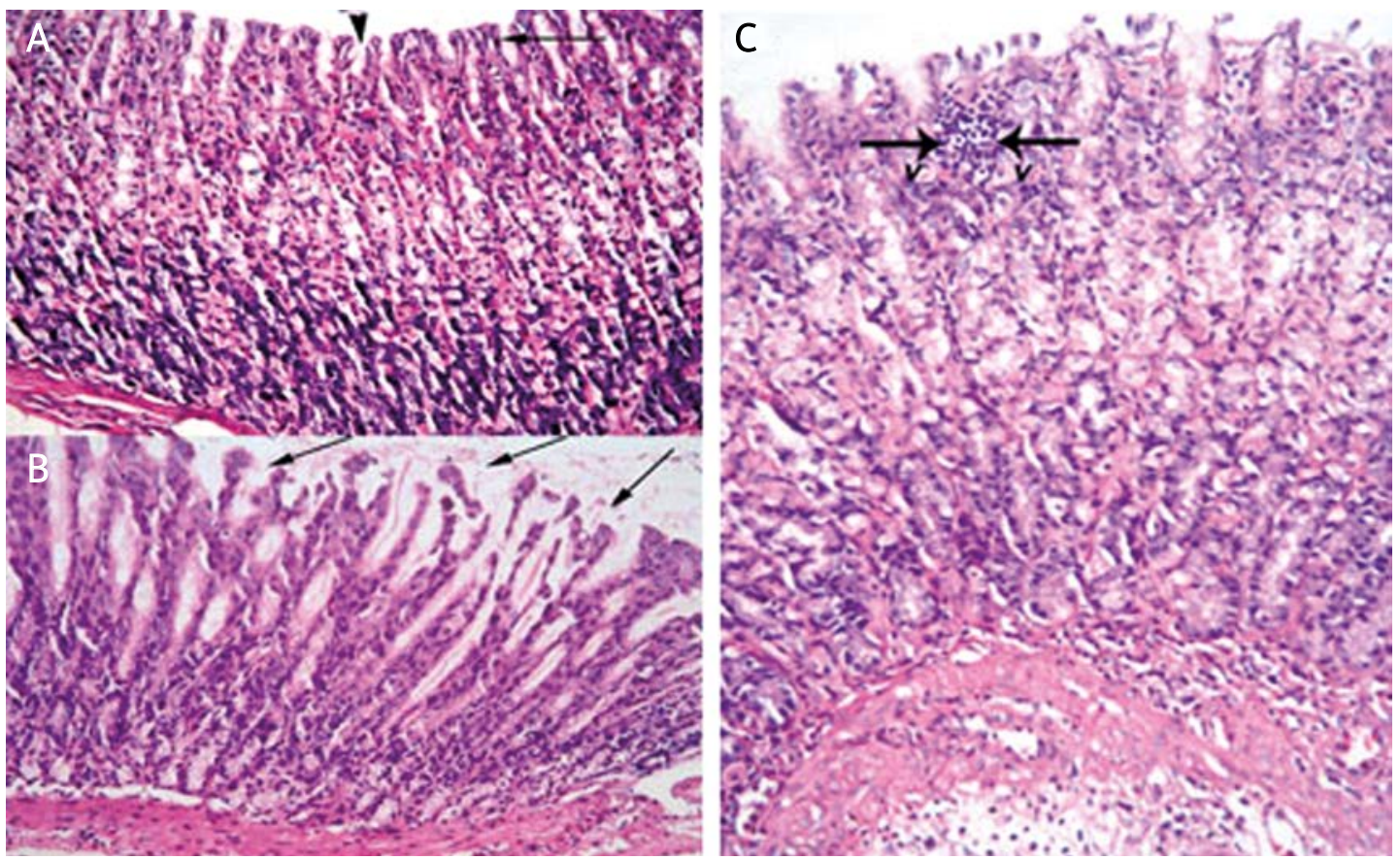

Figure 2. A - Normal mucous neck cells (arrow) and gastric pit (arrowhead) in a control rat $(H+E, 200 x)$. B - Shedding of the superficial epithelial cells (arrows) in a rat of subgroup I (H+E, 200x). C - Lymphocytic infiltration (arrows) in a rat of subgroup I $(H+E, 200 \times)$ 

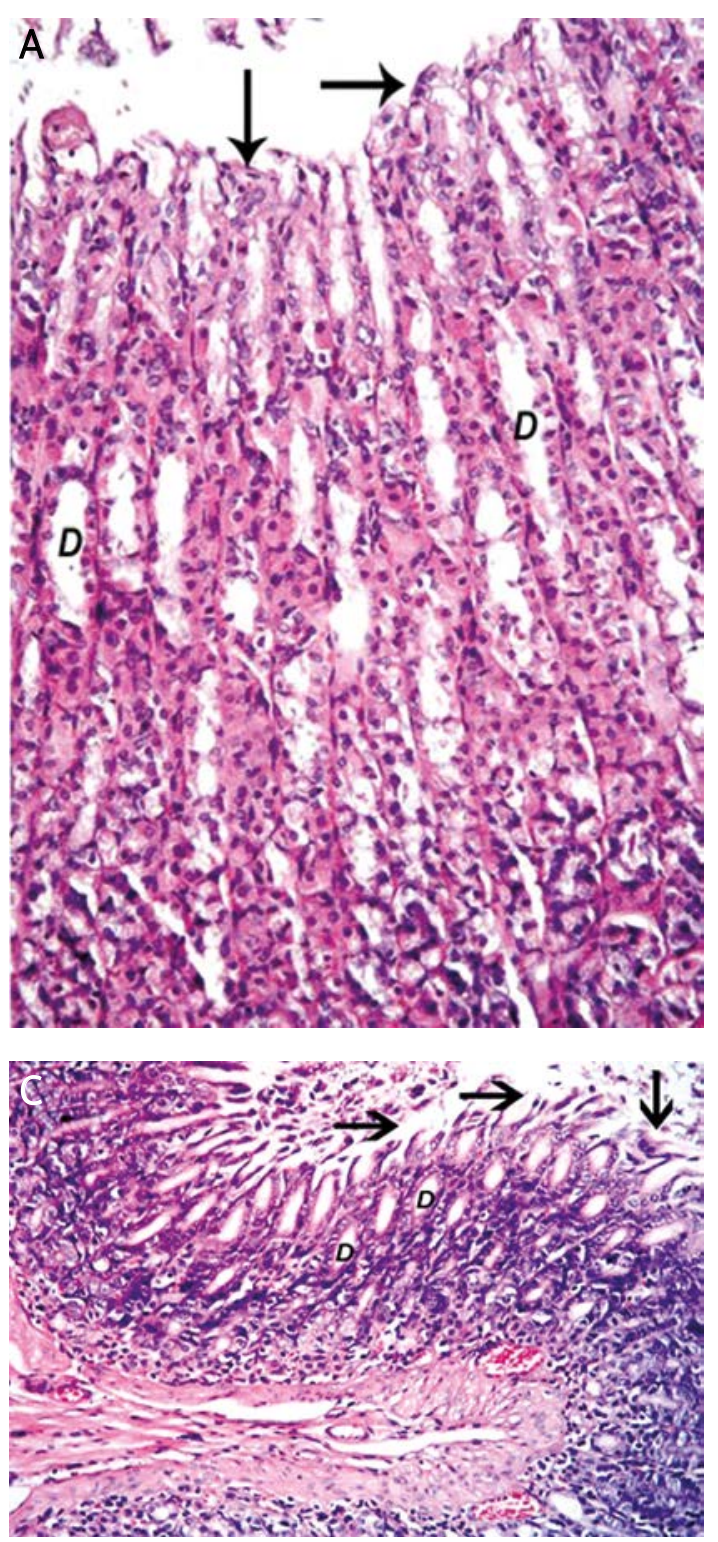

The stomach of the experimental rat subgroups II, III, and IV showed the presence of dilated fundic glands. The surface epithelial cells were normal in subgroups II and III but shredded in subgroup IV (Figure 3).

\section{Results of PAS stained sections}

Loss PAS reaction from the surface cells with its presence in the neck part of the gastric glands was observed in the experimental rats of subgroups I, III and IV (Figures 4 A, C, D). On the other hand, there was a strong PAS reaction at the surface epithelium and at the neck part of the gastric glands (they had violet red granules) in the experimental rats of subgroup II (Figure 4 B), a pattern which closely resembled that of the control group.

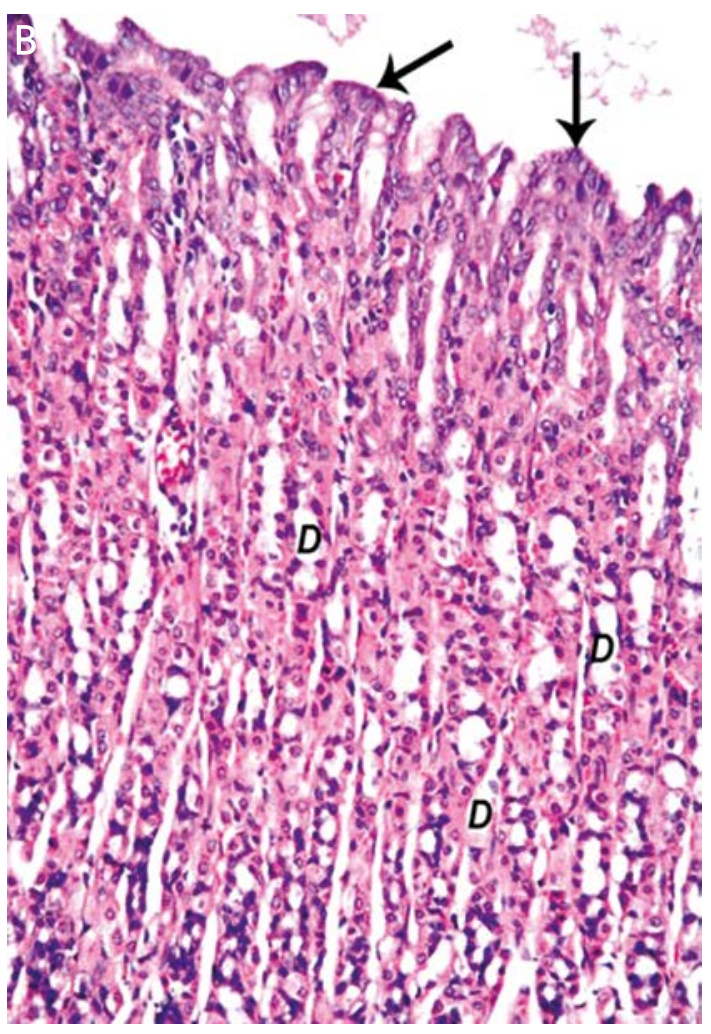

Figure 3. A, B - Dilated fundic glands (D) with normal surface epithelial cells (arrows) in rats of subgroups II and III respectively $(\mathrm{H}+\mathrm{E}, 200 \times)$. C - Shredding of the superficial epithelial cells (arrows) and dilated fundic glands (D) in a rat of subgroup IV $(H+E, 200 x)$

\section{Results of SEM study}

SEM photomicrographs of the stomach of the control rats exhibited the normal mucous cells and gastric pits of the gastric glands with the rugae of the gastric mucosa (Figures $5 \mathrm{~A}, \mathrm{~B}$ ).

The fundus of the stomach of subgroup I rats showed gastric ulcer extending up to the muscularis mucosa. The epithelial cells surrounding the rounded gastric ulcer are the body's attempt to repair the injury by covering the ulcer. Around these cells can be seen the rough texture of healthy gastric mucosa (Figures 5 C, D).

Also, all the experimental subgroups exhibited abnormal surface epithelial cells within the gastric ulcer area (Figure 6). The difference in the size of gastric ulcers between all experimental subgroups 


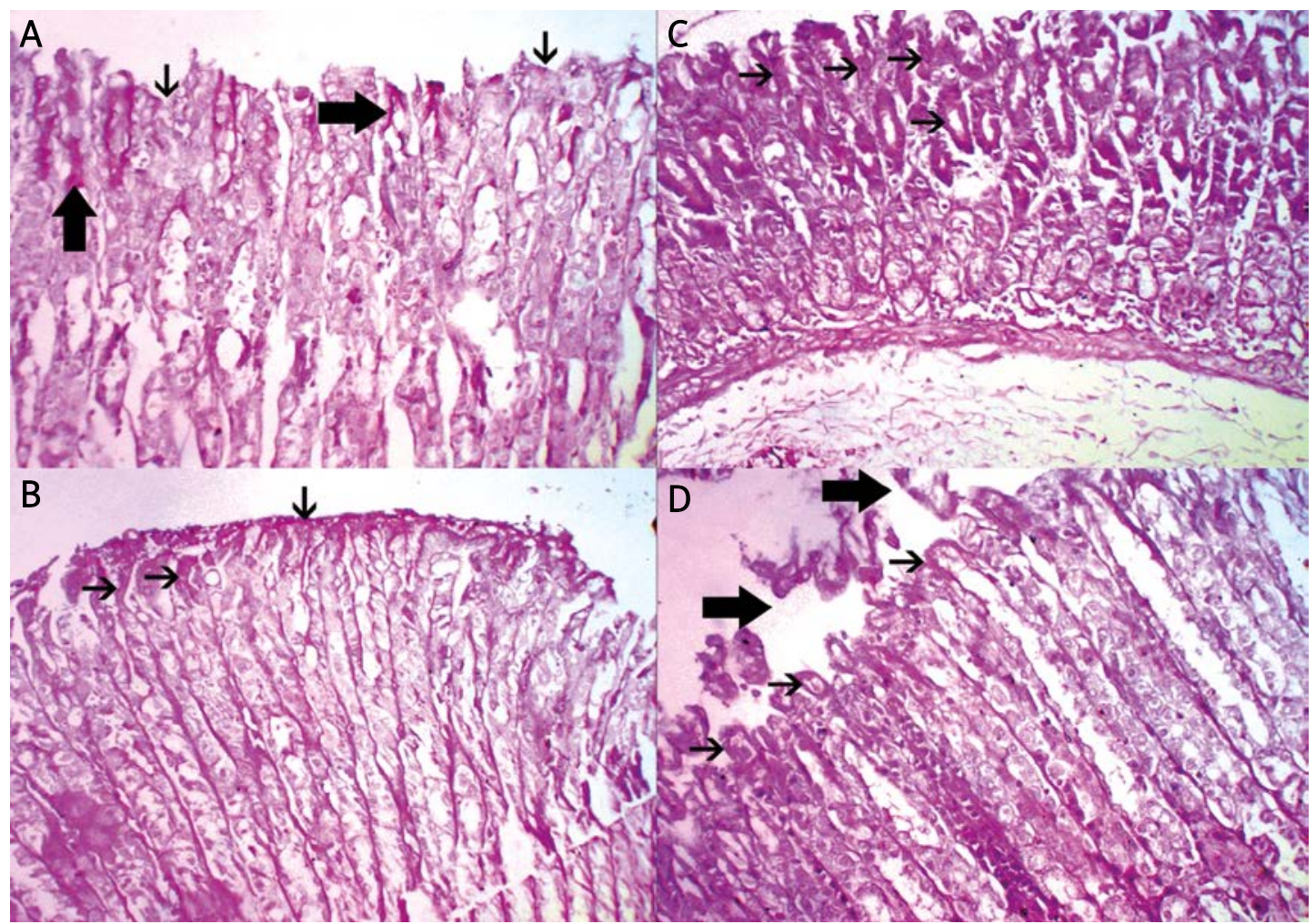

Figure 4. A - Loss of PAS reaction from the surface cells (thin arrows) with its presence in the neck part of the gastric glands (thick arrows) in rat subgroup I (PAS 200x). B, C - PAS reaction at the surface epithelium and at the neck cells of the gastric glands (arrows) in the rat subgroups II and III respectively (PAS 200x). D - Loss of PAS reaction from the surface cells (thick arrows) with its presence in the neck part of the gastric glands (thin arrows) in rat subgroup IV (PAS 200x)

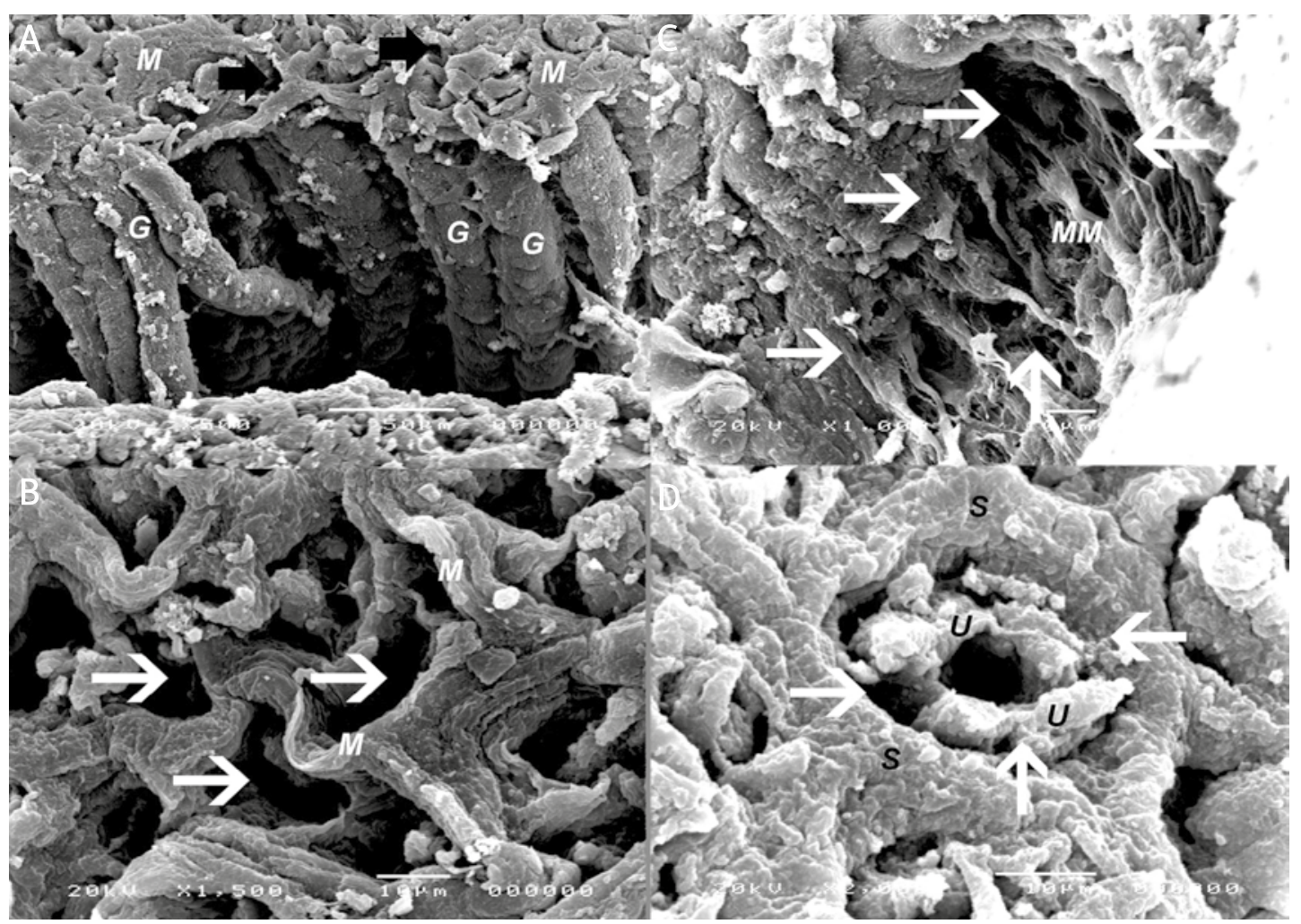

Figure 5. A, B - Normal mucous cells (M), gastric pits (arrows), and gastric glands $(G)$ of the control rats (500x, 1500x respectively). C - Gastric ulcer (arrows) extending up to the muscularis mucosa (MM) in rat subgroup I (1000x). $D$ - Epithelial cells (U) surrounding the rounded gastric ulcer (arrows) in rat subgroup I. Note rough texture of healthy gastric mucosa (S) (2000x) 
was evaluated using SEM, with a noticeable large size of ulcer in subgroup IV compared to other subgroups (Figure 7).
The image analyser study

There was a statistically significant increase in the mean optical density of PAS reaction in the

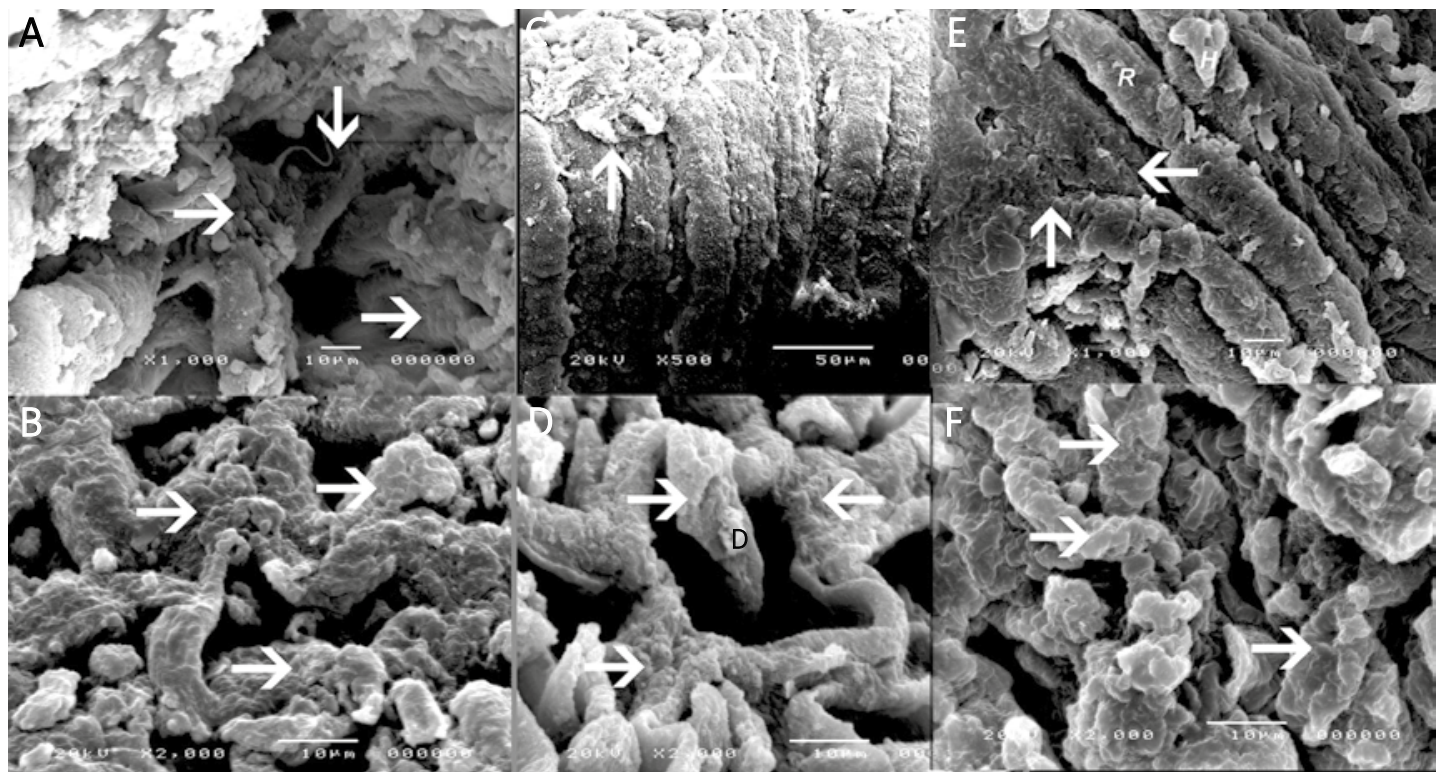

Figure 6. A, B - Surface epithelial cells (arrows) within the gastric ulcer area in rat subgroup II (1000x, 2000x respectively). C - Gastric ulcer (arrows) in rat subgroup III (500x). D - Abnormal surface epithelial cells (arrows) within the gastric ulcer area in rat subgroup III (2000x). E-Absence of rugae (R) at the site of gastric ulcer (arrows) in rat subgroup IV (1000x). F-Abnormal surface epithelial cells (arrows) within the gastric ulcer area in rat subgroup IV (2000x)
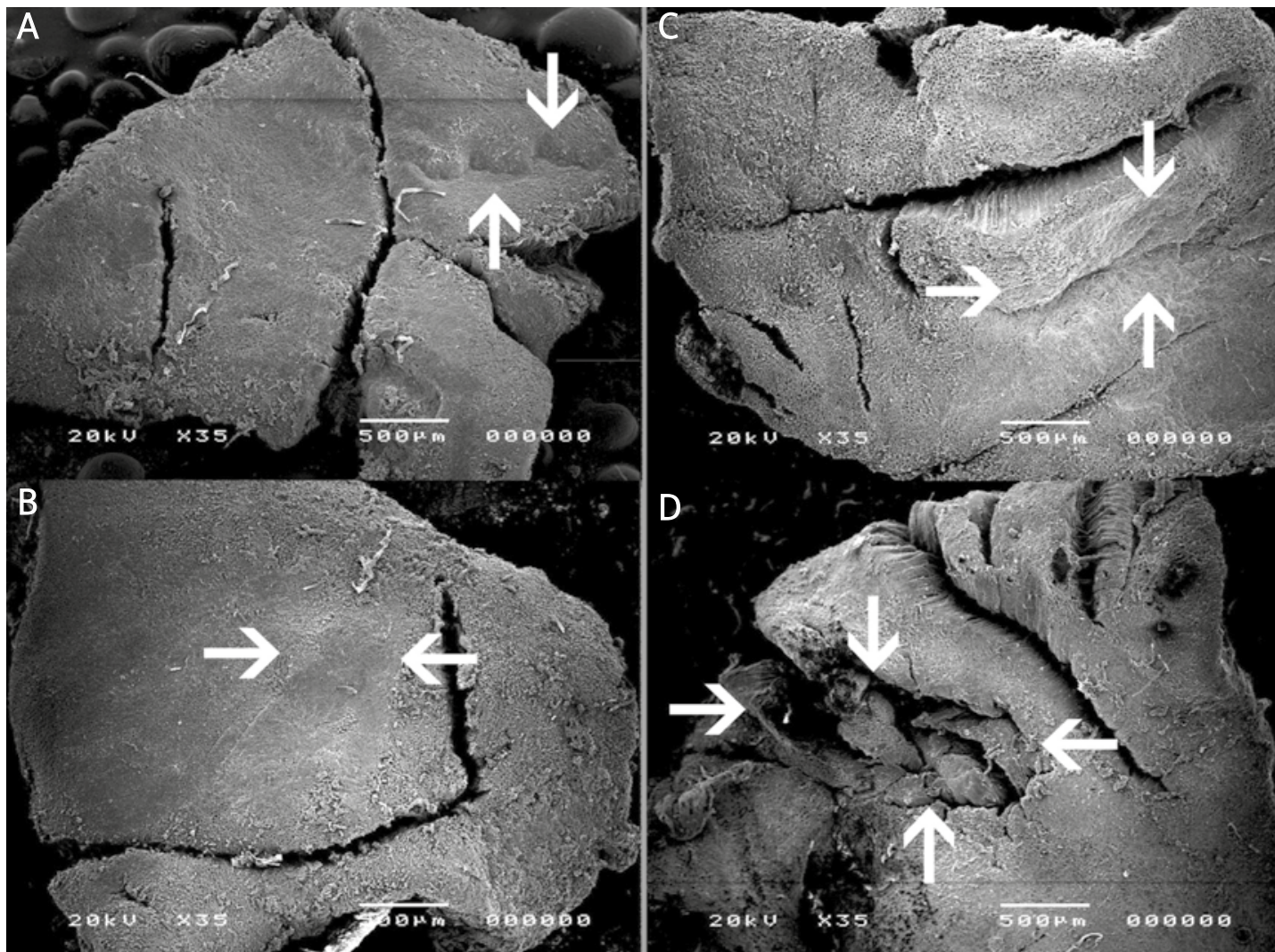

Figure 7. A-D - Scanning electron photomicrographs showing the difference in size of gastric ulcer (arrows) between experimental subgroups I, II, II, IV respectively (35x) 
Table I. Comparison of the mean optical density in the experimental subgroups in relation to the control group

\begin{tabular}{|lcccc|}
\hline Group & $\begin{array}{c}\text { Number } \\
\text { of examined } \\
\text { gastric } \\
\text { preparations } \\
\text { in each group }\end{array}$ & Mean \pm SD & $\begin{array}{c}\text { Value } \\
\text { of } p\end{array}$ & SEM \\
\hline Control & 36 & $0.72 \pm 0.02$ & - & 0.006 \\
\hline Subgroup I & 40 & $0.7 \pm 0.01$ & $>0.05$ & 0.003 \\
\hline Subgroup II & 40 & $0.77 \pm 0.01$ & $>0.05$ & 0.005 \\
\hline Subgroup III & 40 & $0.8 \pm 0.02$ & $<0.01^{*} 0.008$ \\
\hline Subgroup IV & 40 & $0.72 \pm 0.01$ & $>0.05$ & 0.005 \\
\hline
\end{tabular}

*statistically significant difference, SEM - standard error of mean

experimental animals of subgroup III compared to the control group $(p<0.01)$. On the other hand, the mean optical density in the other experimental animals was statistically insignificant when compared to the control group (Table I).

The mean optical density of the animals of subgroups II and III showed a statistically significant increase when compared to subgroup I $(p<0.001)$. In addition, the mean optical density reaction in the animals of subgroups II and III was statistically significantly higher than in subgroup IV $(p<0.001)$ (Table II).

\section{Discussion}

Administration of indomethacin to the experimental rats in the current study induced gastric ulceration and deep erosions with shedding of the superficial epithelial cells. The gastric mucosa was congested and oxyntic cells were vacuolated. The ulcerogenic gastrointestinal side effects of the NSAIDs are among the more serious complications in patients taking these drugs [13]. The latter authors added that prostaglandin (PG) deficiency plays a critical role in the pathogenesis of NSAIDinduced gastric injury. Suppression of prostaglandin synthesis is associated with reduction of gastric mucosal blood flow, disturbance of microcirculation, decrease in mucus secretion, lipid peroxidation, and neutrophil activation, which are involved in the pathogenesis of gastrointestinal mucosal disorders $[14,15]$. Furthermore, the development of the gastric mucosal lesions induced by indomethacin may also be mediated through generation of oxygen free radicals [16].

Cellular infiltration was observed in the connective tissue corium of the basal part of the fundic mucosa in the indomethacin-treated group. This may be attributed to the neutrophil-endothelial cell interactions as a cause of gastric injury in this group.

Also in the previous group, the fundic glands were dilated. This glandular dilatation might be an indication of hypersecretion, which might be related
Table II. Comparison of the mean optical density between the different experimental subgroups

\begin{tabular}{|c|c|c|c|}
\hline Group & $\begin{array}{c}\text { Number } \\
\text { of examined } \\
\text { gastric } \\
\text { preparations } \\
\text { in each group }\end{array}$ & Versus & Value of $p$ \\
\hline \multirow[t]{3}{*}{ Subgroup I } & \multirow{3}{*}{40} & Subgroup II & $<0.001^{*}$ \\
\hline & & Subgroup III & $<0.001^{*}$ \\
\hline & & Subgroup IV & $>0.05$ \\
\hline \multirow[t]{2}{*}{ Subgroup II } & \multirow{2}{*}{40} & Subgroup III & $>0.05$ \\
\hline & & Subgroup IV & $<0.001^{\star}$ \\
\hline Subgroup III & 40 & Subgroup IV & $<0.001^{*}$ \\
\hline
\end{tabular}

to inhibition of prostaglandin $\mathrm{I}_{2}$, a potent anti-secretory agent [17]

The epithelial cells surrounding the rounded gastric ulcer were observed in the previous group: an attempt by the body to repair the injury by covering the ulcer.

Indomethacin at ulcerogenic doses induces a rise in corticosterone, which helps the gastric mucosa to resist the harmful actions of these ulcerogenic agents $[18,19]$, so dexamethasone, which is a potent corticosteroid, was used in the current study in an ulcerogenic, pharmacological dose. The current study was designed to study the effects of varying the time of GC on indomethacin-induced gastric erosions.

The stomach of the dexamethasone-treated rats of subgroups II, III and IV showed the presence of dilated fundic glands. The oxyntic cells and the surface epithelial cells were normal in subgroups II and III but with prolongation of time, they were affected in subgroup IV. The ulcer sizes in the latter subgroup were noticeably bigger when compared to the other experimental subgroups. The aggravation of the actions of GC treatment on the formation of indomethacin-induced erosions may be mediated by inadequate production of GC hormones resulting from the suppression of the hypothalamo-hypophyseal-adrenocortical system [20]. In addition, the disturbance of carbohydrate regulation accompanied by the catabolic effects of the GC may also be responsible for the ulcerogenic action of dexamethasone [21].

All the experimental subgroups exhibited the abnormal surface epithelial cells within the gastric ulcer area. The mechanism for ulcer repair represents a process including the balance of cell damage and repair at the ulcer site. The GC in ulcerogenic doses could not only damage the mucosa but also affect the regenerative system in the gastric mucosa by inhibiting the epithelial cell proliferation and angiogenesis at the ulcer margin and base [21, 22]. These adverse actions of GCs on gastric ulcer 
healing are due to their inhibiting COX-2 expression and $P G E_{2}$ formation [22, 23].

Cellular infiltration was absent in the dexamethasone-treated rats as GC in pharmacological dose inhibits the proinflammatory activities of transcription factors, in particular nuclear factor $\kappa B$ [24].

There was a statistically significant increase in the mean optical density of PAS reaction in the experimental animals of subgroup III compared to the control group. On the other hand, the mean in the other experimental animals was statistically insignificant when compared to the control group. In addition, there was a statistically significant increase of the mean in the animals of subgroups II and III when compared to subgroup I. These findings denoted increased activity of the mucous surface and neck cells in forming new coating mucus to protect the gastric mucosa against further injury. In addition, the excess abnormal epithelial cells surrounding the gastric ulcer are another cause of the high mean in the experimental subgroups.

On the other hand, there was a statistically significant increase of the mean in the animals of subgroups II and III when compared to subgroup IV. This may be attributed to ulcer sizes in the latter subgroup, which were noticeably bigger than in the other experimental subgroups.

In conclusion, indomethacin is capable of producing injury to gastrointestinal mucosa. The GC in their pharmacological doses could not only damage the gastric mucosa but also affect its regenerative system. With prolonged time the surface epithelial cells became more affected, and the ulcer sizes became noticeably bigger. Concomitant use of both medications will obviously delay the healing of the indomethacin-induced gastric ulcer and possibly induce more gastric complications especially with the prolonged use of GC. So, it is recommended to meticulously follow up patients who take both medications concomitantly to avoid any possible complication of gastric ulcer.

\section{References}

1. Naito Y, Kuroda M, Mizushima K, et al. Transcriptome analysis for cytoprotective actions of rebamipide against indomethacin-induced gastric mucosal injury in rats. J Clin Biochem Nutr 2007; 41: 202-10.

2. Hawkey CJ. Nonsteroidal anti-inflammatory drug gastropathy. Gastroenterology 2000; 119: 521-35.

3. Rhen T, Cidlowski JA. Anti-inflammatory action of glucocorticoids-new mechanisms for old drugs. N Engl J Med 2005; 353: 1711-23.

4. Gallant C, Kenny P. Oral glucocorticoids and their complications. A review. J Am Acad Dematol 1986; 14: 161-77.

5. Filaretova LP, Filaretov AA, Makara GB. Corticosterone increase inhibits stress-induced gastric erosions in rats. Am J Physiol 1998; 274: G1024-30.

6. Takeuchi K, Ohtsuki H, Okada M, et al. Proulcerogenic and mucosal protective action of glucocorticoid in the rat stomach. Asia Pac J Pharmacol 1989; 31: 219-25.
7. Filaretova L, Morozova O, Bagaeva T, Podvigina T. From gastroprotective to proulcerogenic action of glucocorticoids on the gastric mucosa. J Physiol Pharmacol 2009; 60 (Suppl. 7): 79-86.

8. Arisawa T, Harata M, Kamiya Y, et al. Is omeprazole or misoprostol superior for improving indomethacin-induced delayed maturation of granulation tissue in rat gastric ulcers? Digestion 2006; 73: 32-9.

9. Singh LP, Mishra A, Saha D, Swarnakar S. Doxycycline blocks gastric ulcer by regulating matrix metalloproteinase2 activity and oxidative stress. World J Gastroenterol 2011; 17: 3310-21.

10. Wallace JL. Pathogenesis of NSAID-induced gastroduodenal mucosal injury. Best Pract Res Clin Gastroenterol 2001; 15: 691-703.

11. Bancroft JD, Gamble M. Theory and practice of histological techniques. $5^{\text {th }}$ ed. London: Churchill Livingstone; 2002. p. 167-70.

12. Michael J. Dykstra, Laura E. Reuss. Biological electron microscopy: theory, techniques, and troubleshooting. $2^{\text {nd }}$ ed. New York: Library of congress; 2003. p. 74-100.

13. Filaretova LP. Gastroprotective role of glucocorticoid hormones during action of nonsteroidal anti-inflammatory drugs [Russian]. Ross Fiziol Zh Im I M Sechenova 2009; 95: 250-61.

14. Wallace JL. Pathogenesis of NSAID-induced gastroduodenal mucosal injury. Best Pract Res Clin Gastroenterol 2001; 15: 691-703.

15. Kaneko T, Matsui H, Shimokawa O, Nakahara A, Hyodo I. Cellular membrane fluidity measurement by fluorescence polarization in indomethacin-induced gastric cellular injury in vitro. J Gastroenterol 2007; 42: 939-946.

16. Kim JH, Kim BW, Kwon HJ, Nam SW. Curative effect of selenium against indomethacin-induced gastric ulcers in rats. J Microbiol Biotechnol 2011; 21: 400-4.

17. Ng CJ, Chen JC, Chiu DF, Chen MF, Chen HM. Role of prostacyclin on microcirculation in endotoxin-induced gastroprotection in rats: a microdialysis study. Shock 2002; 17: 334-38.

18. Filaretova L, Bagaeva T, Podvigina T, Makara G. Various ulcerogenic stimuli are potentiated by glucocorticoid deficiency in rats. J Physiol Paris 2001; 95: 59-65.

19. Filaretova L, Podvigina T, Bagaeva T, Makara G. Gastroprotective action of glucocorticoids during the formation and the healing of indomethacin-induced gastric erosions in rats. J Physiol Paris 2001; 95: 201-8.

20. Morozova OY, Bagaeva TR, Filaretova LP. Suppression of hypothalamo-hypophyseal-adrenocortical system function as the cause of aggravation of the ulcerogenic action of indomethacin on the stomach after administration of pharmacological doses of hydrocortisone. Neurosci Behav Physiol 2010; 40: 117-22.

21. Podvigina TT, Morozova O, Bagaeva TR, Filaretova LP. Effect of dexamethasone on indomethacin-induced gastric erosion formation upon duration of the hormonal action [Russian]. Ross Fiziol Zh Im I M Sechenova 2009; 95: 72635.

22. Luo JC, Shin VY, Liu ES, et al. Non-ulcerogenic dose of dexamethasone delays gastric ulcer healing in rats. J Pharmacol Exp Ther 2003; 307: 692-8.

23. Luo JC, Shin VY, Liu ES, et al. Dexamethasone delays ulcer healing by inhibition of angiogenesis in rat stomachs. Eur J Pharmacol 2004; 485: 275-81.

24. Yang YX, Lichtenstein GR. Corticosteroids in Crohn's disease. Am J Gastroenterol 2002; 97: 803-30. 